ISSN: 2162-3104 Print/ ISSN: 2166-3750 Online

Volume 8, Issue 3 (2018), pp. 1440-1458

(C) Journal of International Students

http://jistudents.org/

doi: 10.5281/zenodo. 1254607

\title{
Developing a Host Culture for International Students: What Does It Take?
}

\author{
Samantha Marangell \\ University of Melbourne, Australia \\ Sophie Arkoudis \\ University of Melbourne, Australia \\ Chi Baik \\ University of Melbourne, Australia
}

\begin{abstract}
This article argues that international student integration is not only a university issue, but a community one. Thus, the next step for universities' internationalization strategies requires expanding efforts to include engagement with the greater community and bringing a community-based approach to internationalization processes. Doing so will both better serve the international student population and also create a more well-rounded internationalized university experience for all students by acknowledging and harnessing the inherent diversity of the local community. In particular, this article discusses the university's role in facilitating such a communitybased approach. It will then examine possible strategies and practical suggestions for how universities can step beyond campus-specific policies and instead foster student engagement with and within the greater local community.
\end{abstract}

Keywords: community engagement, higher education, international students, internationalization, social integration, student experience

The internationalization of higher education has been a prominent focus of discussion among researchers, higher education administrators, and policymakers for over two decades. During this time, many initial aims of 
building capacity and international standards have been replaced with a focus on the commercial benefits of recruiting large international student populations. The persistent challenge of integrating those international students into the university community suggests that the available strategies are limited and that it is time to shift our internationalization approach to one that has a more far-reaching potential.

Dynamic increases in student mobility have affected the internationalization of higher education institutions around the world as the number of tertiary students who are studying outside their home country continues to increase dramatically. In 2016, approximately five million tertiary students studied in another country, an increase of 67 percent since 2005 , and that number is speculated to increase to 8 million students by 2025 (ICEF Monitor, 2016). A high concentration of these mobile students choose to study in English-speaking countries and at English-medium universities, creating learning environments that are rich with possibilities for cultural and linguistic exchange but also opportunities for tensions to arise around language, conflicting expectations, and differing academic practices.

Universities and researchers have reacted to this influx by primarily focusing on improving the experience of this large international cohort and on helping international students from non-English-speaking backgrounds succeed in English-speaking universities. Key efforts have been enacted to help students adjust to university life, with heavy emphasis on the international student doing the adjusting, adapting, and changing. Specific focus has been put on improving international students' English-language proficiency and in improving their academic skills (Baik \& Greig, 2009).

As a result of these efforts, international students generally perform well enough academically, meaning that they are likely to pass their studies, though their marks do not tend to be as high as those of domestic students (Norton, 2016). Despite well-documented language and integration issues, responses on the International Student Barometer suggest that international students are generally satisfied with their study experience (Department of Education and Training, 2017).

However, these efforts do not adequately provide an "equitable student experience for international students" (Proctor \& Arkoudis, 2017, p. 129), because they often inadvertently emphasize the experience of international students and overlook the wider aspects of internationalization such as the development of global perspectives (Lunn, 2008). While some universities embrace a holistic approach to internationalization that incorporates top-down and bottom-up efforts, such positive examples are less common (Lunn, 2008). Issues such as increased commercialization and 
emphasis on economic rationales for internationalization pose challenges for many universities (Jones \& de Wit, 2012). Most notably, difficulties have persisted in successfully integrating international students into the local community (Arkoudis et al., 2010). Thus, a combination of the ever-shifting student experience and the endurance of specific challenges suggests that it is time to welcome an approach to internationalization that considers the wider context and embraces a broader, more community-driven priority.

In this article, we propose a more community-based approach to internationalization with the aim of better fostering a supportive, wellrounded, internationalized learning experience for all students. First, we outline some of the current challenges facing the internationalization of higher education institutions and tensions around the integration of international students. Next, we discuss the ways that those challenges take shape within the community-university relationship. Finally, we provide practical suggestions for implementing a community-based approach that keeps these challenges in mind.

\section{CURRENT CHALLENGES IN INTERNATIONALIZATION}

The literature consistently shows that there remain tensions around student interactions. In many environments, students from different cultural or linguistic backgrounds do not freely interact with each other (Arkoudis et al., 2010; Pham \& Tran, 2015). This seems to be the case across a range of host countries and with students from all backgrounds. Not only do international students demonstrate difficulty integrating into the host community, but even in the classroom, students tend to associate with those who are culturally or linguistically similar (Arkoudis et al., 2010; 2012). In addition, there exist a range of intercultural challenges that may inhibit interaction on the part of both domestic and international students, including language difficulties (Arkoudis et al., 2010), differing communication styles (Straker, 2016; Zhang, 2015), anxiety (Dunne, 2009), a lack of common interests (Arkoudis et al., 2010), differing schedules (Arkoudis et al., 2010; Kondakci, Van den Broeck, \& Yildirim, 2008), and feeling judged by other students (Dunne, 2009; O'Reilly, Hickey, \& Ryan, 2013). Such reluctance to interact despite proximity and contact has been exhibited in institutions of higher education in multiple countries, including English-speaking countries such as the US, Australia, Ireland, the UK, and Canada, as well as nonEnglish speaking countries such as Finland, Belgium, and Japan (cf. Arkoudis et al., 2010; Dimitrov, Dawson, Olsen, \& Meadows, 2014; Dunne, 2009; Etherington, 2014; Harrison \& Peacock, 2010). 
This perceived lack of positive, substantial interaction between domestic and international students is a major challenge of internationalization (Arkoudis et al., 2010; Yates \& Wahid, 2013). A lack of interaction between diverse students can slow international students' English language development (Etherington, 2014), reduce the opportunities for all students to gain global perspectives (Arkoudis et al., 2010), and result in feelings of dissatisfaction and isolation (Kormos, Csizér, \& Iwaniec, 2014; Rochecouste \& Oliver, 2014; Yates \& Wahid, 2013). Additionally, peer interaction within learning environments is believed to aid comprehension of the learning material (Arkoudis et al., 2010; Etherington, 2014), assist academic achievement (Akanwa, 2015), and prepare students for intercultural workplaces (Etherington, 2014).

Researchers agree that contact alone is not enough of an impetus for interaction and that interaction needs to be managed and facilitated in order to be successful (Harrison \& Peacock, 2010). However, the more problematic aspect is that interaction between international and domestic students, if poorly managed, may also result in negative interaction experiences and subsequently lead to feelings of resentment by all parties. This is particularly evident by students' frequent referral to the "other" as being "excluding." Such homophily, or spending time with only those of the same background, is frequently interpreted as a barrier to interaction (Arkoudis et al., 2010; 2012). However, Centola et al. (2007) have coined the term "induced homophily" to explain that interaction may not only be affected by segregatory behavior but that it can produce homophilic behavior as well, meaning it may actually encourage students to spend time only with those of the same background. At the same time, researchers disagree on the role of proximity and familiarity in intercultural relations. Some highlight their potential for reducing biases (Bornstein, 1989, cited in Kormos, Csizér, \& Iwaniec, 2014) and others warn that proximity can lead to homophilic behavior and feelings of threat (Dunne, 2013; Koen \& Durrheim, 2010). These conflicting outcomes, then, emphasize that the result of interaction is not only uncertain but that interaction itself has risks when not managed actively.

One potential risk is the feeling of resentment towards fellow students. Currently, there exists an alarming perception among some domestic students that the quality of education is lowered due to the presence of international students, that grades are negatively affected by group work with international students, and that entry requirements have been lowered for international students (Barron, 2006; Harrison \& Peacock, 2010; Strauss, U-Mackey, \& Crothers, 2014; Sweeney, Weaven, \& Herington, 2008). These combined factors can lead to resentment on the part 
of the domestic students and a feeling of unfairness that Barron (2006) warned over a decade ago was the most potentially problematic response from domestic students. Yet, over these last ten years, little work has been done to reduce such resentment or even identify what causes it. Importantly, this resentment may occur even as domestic students state explicitly that they understand the benefits of multicultural interaction, intercultural study, and multicultural group work (Barron, 2006). International students also understand the benefits; however, the preconceived notions they each hold about interacting and the fear that this causes (of offense, anxiety, and low grades) can take precedence. These are some of the many contradictions in the literature between what students seem to "know" and how they behave.

While we know little about what can reduce this resentment, it appears that the potential for such resentment may increase when the proportion of international students reaches a critical mass. Parsons (2010) explains this as domestic students' potential fatigue over having to frequently overcome the difficulties of working with international students. However, for international students, it also seems to matter that the size of the particular co-national group is large enough for students to depend on. The lack of opportunity to fall back into culturally similar circles may be the necessary push international students need to embrace the risks of interacting with domestic students (Edgeworth \& Eiseman, 2007). Especially when there is an existing, comfortable network of peers, there may be less of a need for, and more of a risk in, multicultural interaction. In fact, domestic and international students may both focus on the risks of interacting, rather than the benefits (Harrison \& Peacock, 2010). In addition, an outwardly diverse student body can also lead to feelings of apathy and anonymity among the students, resulting in an unintended justification for their lack of interaction (Halualani, 2010). In such circumstances, many students believe that passive forms of interaction such as sitting in the same room can suffice as intercultural interaction (Halualani, 2008). Thus, the continuing increase of the incoming international student population may start to exacerbate the potential for homophily among all students and, thus, feelings of resentment as well.

Though such attitudes may be heightened by university environments, they often do not start in the classroom. Instead, they are a symptom of greater societal issues. Harrison (2015) argues that we have to "situate any discussion about [internationalization] in a wider context of inequalities, social mobility and class transmission" (p. 424). Other authors highlight the potential racial tensions and social challenges that will likely bleed into student relations (Lantz-Deaton, 2017), especially as the number of international students increases (Ritter, 2016). 
A review of the existing literature suggests that current strategies appear to have a limited ability to solve these issues of apathy, resentment, and active avoidance, primarily because they focus only on the academic environment. By being academic-centered, most interaction-promoting strategies ignore the social issues and tensions that the students bring with them, and simultaneously disregard students' fears of reduced grades, communication challenges, and conflicting expectations. In addition to focusing only on the academic challenges, current strategies are also limited in who they assist. At the moment, the students who show most improvement in their intercultural skills are those with existing dispositions toward intercultural interests (Harrison \& Peacock, 2010). This is partly because most on-campus activities around internationalization are geared toward the study abroad experience and do not benefit the "non-mobile majority" (Beelen \& Jones, 2015, p. 68), likely the student group that is least inclined to naturally seek out multicultural experiences. A third issue is that international students are often positioned as the inferior party, despite discussion in the literature to move away from a "deficit model" which portrays international students as the unskilled party (Dunne, 2013, p. 572). This unequal power distribution is commonly demonstrated in the establishment of peer mentoring programs that position the domestic student as the "mentor," perpetuating the idea that it is only the international student who needs to adjust.

These academic-centered efforts also put unfair pressure on individual instructors. Arkoudis et al. (2010) and Etherington (2014) note that some teachers may be subject specialists but are not well versed in educational theory, and, thus, are not prepared to adapt their teaching style to different cultures of learning or to English language learners. Similarly, teachers of particularly content-heavy courses might not have the time to fit more multicultural, discussion-based activities into their lessons (Arkoudis et al., 2010; Arkoudis \& Baik, 2014; Etherington, 2014) nor include additional intercultural competencies in their lesson aims (Etherington, 2014).

We propose that it is time for universities to move beyond the idea that internationalization strategies can be limited to either the classroom or the campus. Instead, we present the concept of a community-based approach to internationalization that would foster a more far-reaching and tolerant host culture, offering opportunity, interaction, and respect for international students. In the following sections, we first outline our reasons behind such an idea and then offer practical suggestions for how to implement such an approach. 


\section{THE RELATIONSHIP BETWEEN THE UNIVERSITY AND THE BROADER COMMUNITY}

Despite how well international students may do academically, there is consistent evidence that they are often unable to successfully integrate into the host community. This circumstance is demonstrated in Anglophone communities throughout the world, even though over one third of student life is spent within the host community (Arambewela \& Hall, 2013). Cultural integration, specifically, may not be as important to adjustment as academic preparation (Seow, 2005), but being part of a social community has been shown to make the transition to the new environment much smoother for international students (Gautam, Lowery, Mays, \& Durant, 2016; Romerhausen, 2013). In addition, interaction with the host community is a primary aid to not only cultural adaptation (Yu \& Wright, 2016), but to student satisfaction (Arambewela \& Hall, 2013; Bianchi, 2013) and future employability (Arkoudis \& Baik, 2014). The community environment may, in fact, have a larger influence on student satisfaction than the university environment (Arambewela \& Hall, 2013). Nevertheless, international students do not easily integrate into the host community.

On the other hand, the marked increase in international student enrollments has long benefited the host communities in which these students study. While it is impossible to quantify all the benefits that international students bring, there are some easily recognizable economic benefits, primarily in students' spending on tuition and fees (Vickers \& Bekhradnia, 2007). International students in Australia, for example, are estimated to contribute around A $\$ 20$ billion annually (US\$15.5 billion) (Deloitte Access Economics, 2016). This financial contribution includes far more than university costs. Communities also benefit financially through increased employment, hospitality, accommodation, and everyday spending (Deloitte, 2016; Group of Eight Australia, 2014). International students also attract other tourists, bringing around 160,000 overseas visitors to Australia (Group of Eight Australia, 2014).

There are consistent non-financial benefits to the community as well, particularly in improved cultural literacy and cultural capital (Deloitte, 2016). The community's projected image becomes more favorable due to the diversity of the population, the increase of cultural influences, and the image of openness and progressiveness that such multicultural populations bring with them. Transnational connections also offer potentially huge benefits to Australian businesses (Tran \& Gribble, 2015).

Yet, there is very little reciprocity in community benefits that are returned to the international students. International students often meet more 
hardships than favors, specifically regarding issues with employment, accommodation, exploitation, discrimination, and cultural segregation (Kinnaird, 2015; Knight, 2017; Ryan et al., 2016). In many host environments, international students find it incredibly difficult to find employment, either because of working regulations, lack of familiarity with employment processes, English language competency, or because of the circular logic that one should already have had previous work experience in the host country in order to get further work experience in that country (Arkoudis et al., 2009; Gribble, 2014; Lee \& Rice, 2007). As a result, students often end up with work options where they are paid "under the table" for nominal sums under unfair working conditions, unable to speak up about the circumstances out of fear that they would have no other opportunity for employment should this option no longer exist (Lee \& Rice, 2007).

Likewise, international students are often housed in substandard living environments, sleeping multiple to a room with little privacy, no lease, and under seriously pitiful conditions (Knight, 2017; Ryan et al., 2016; Tovey, 2009). The circumstance of many international students living in squalor is documented in at least Australia, the US, and the UK (Ryan et al., 2016). For many, such accommodation is the only possible option because international students may not have the local references and rental history that may be required for more well-maintained accommodation, city housing prices are often unaffordable, and university-managed accommodation may not meet demand (Ryan et al., 2016; Tovey, 2009). Yet occupants without leases are vulnerable to hidden fees and spontaneous rent increases, and they often feel unable to speak up against unfair treatment for fear of their visas being revoked and their only housing option removed (Ryan et al., 2016; Tovey, 2009). These factors combine to put international students' safety and wellbeing at great risk (Ryan et al., 2016).

Lastly, the issue of cultural segregation deals with the fact that international students are not always integrated or welcomed into the community (Lee \& Rice, 2017). Of course, each of these situations requires an acceptance on the part of the students as well, but the frequency of the phenomena poses a worrisome challenge for both the international student experience and the students' relationships with the community.

As a response to these challenges, many international students take advantage of extensive support networks established by their cultural group outside of the university that often include childcare, employment opportunities, and housing networks. While these systems may have originally been born out of the necessity for support, they may now act unintentionally as reasons to further avoid integration with the larger 
community. These supports undoubtedly provide valuable assistance for students without any other networks, and, of course, we cannot ignore the fact that some students study internationally without any intention or desire to integrate; yet, there are other students who would like to become part of the host community if given the opportunity. At the moment, the opportunity rarely exists, and when it does, it is frequently met with pushback.

Universities have certainly taken many steps to try mitigating these issues, including starting mentor programs, adding more group work to the curriculum, and promoting "know your rights" campaigns. Yet universities only have so much reach and influence when the source of the problem is societal. As long as there continues to be a disconnect between the universities - international students' primary connection to the community - and the off-campus, host community, universities' interventions can only remain limited and superficial.

This puts universities at a particular disadvantage, as many issues in the classroom are born directly from community tensions, including racism, segregation, exploitation, and active avoidance of cross-cultural interaction. As mentioned earlier, we cannot isolate discussion on internationalization without also discussing the greater social context, because the two are interdependent. For example, the foreign community with the largest presence on campus is often also that with the largest presence in the community, and, as a result, is the cultural group that often experiences the most targeted prejudice and scapegoating. Feelings of specific resentment, prejudice, and social stigma also overflow into the classroom environment where stereotypes - both positive and negative-often inform student interactions. On the other hand, communities that are genuinely more tolerant of diversity and multilingualism also tend to support more tolerant classroom environments where polylingualism is seen as a resource rather than a hindrance. However, many international students believe that they should accept discrimination as a natural cost of their education in Anglophone countries (Lee, 2007). The harassment they experience, though, has a direct effect on the classroom experience.

Harassment due to appearance has become particularly notable, with "foreign looking" students being yelled at from passing cars (Khawaja \& Stallman, 2011) or even having bottles thrown at them (Lee, 2007). Many experiences, such as the preceding two examples, often occur when walking home from class, an activity that sits at the blurry border between community and university. Even students' definitions of "culture," and who they interact with, is often based on more general societal assumptions. International students in the United States, for example, have been known to 
build stereotypically negative attitudes towards Latinos only after arriving in the US and being surrounded by existing prejudices and misconceptions (Ritter, 2016). Assumptions about who is "worthy" of interaction have palpable and direct consequences for the internationalized classroom. Until these issues are addressed, they will continue to affect the social dynamic between domestic and international students. Thus, universities are not only well-placed to advocate on behalf of international students, it will also be in their best interest to pursue a better solution to these community-based challenges.

\section{A COMMUNITY-BASED APPROACH}

Based on the literature described above, it is clear that international students are integral contributors to the broader community, but universities are naturally the students' primary focus and community hub during their studies. In order to move forward with internationalization efforts and engage with the community as a whole, the university needs to embrace a community-spirited approach where the role of the university is one of advocate on behalf of the international students towards the community.

This shift in perspective is the first and most fundamental change we propose, on top of which the other suggestions depend. It requires that universities serve as the students' link and spokesman in the community. There needs to be a proactive acceptance that the university is not isolated from the community, nor vice versa, and so universities must take an active role in establishing a solid relationship with the community organizations that most directly affect their students. It will not do to say that they serve as a link to the community simply by bringing new students to that community. Instead, they must establish firm relationships with community groups, agencies, and organizations that are built on bi-directional advising, respect, and program planning. Wherever possible, universities and communities need to establish practices and policies together, in a manner that holds all parties accountable. All other suggestions hinge on the acceptance of this fundamental role. Once that role is adopted by the university, the following practical steps can offer more specific ways to move forward in this capacity.

\section{Practical Step 1: Community-Based Projects}

In addition to policy-making, universities need to expand their use of community-based projects. At the moment, only a small portion of programs utilize community-based projects as part of the curriculum. While many of these programs already offer well-designed opportunities for innovation and community engagement, we agree with Smith and Sobel 
(2010) that such place-based education is applicable to all disciplines. Thus, we argue that a version of this can be implemented in almost all faculties and should be done so for credit and in a facilitated, purposeful manner, rather than on an elective, make-your-own-experience basis.

These projects would be facilitated with a wide range of community groups that would keep the international students in mind. Specifically, rather than expecting the students to establish their own relationships when they would be likely to resort to familiar cultural groups, students would instead be connected to community organizations through relationships established by the university, thus connecting students with organizations with which they would otherwise not be connected. This would allow for the promotion of cross-cultural experiences and for positioning the student population as a diverse and invaluable resource.

Next, in arguing that almost all faculties can and should benefit from such a program, we understand that some faculties, such as business, often do engage practices in which groups of students solve specific problems for community groups. We also understand that not all programs will be so direct. At the very least, though, all programs could require some type of community-immersed activity which includes cooperation with classmates, accountability, assessment, and reflection on the part of the students. As examples of unobtrusive activities, first-year students could complete reflection journals on their observation of a number of outside locations; students could be required to give presentations to community groups; one-semester internships could be completed for credit, rather than pay, in a wide variety of fields; volunteering could be established as a forcredit portion of a particular course. However, we emphasize again that even the observations and volunteering would need to be arranged by the university and with diverse organizations so that mutual expectations and accountability are established. Likewise, even the less structured activities, such as volunteering, would need to require intentional, well-designed reflection.

The third characteristic of these programs is that they be completed for university credit and be required of all students. There are two primary reasons for this. First, it is already problematic that only a small portion of students seem to benefit from cross-cultural or intercultural activities. Relying on students to select these options as electives almost guarantees that the uninterested majority will continue to avoid intercultural experiences. Likewise, we cannot assume that students will proactively embrace the benefits of these programs when they have so far learned that the risks of intercultural interaction often outweigh any benefits. By making these programs required, even for a short intensive period, it would reach 
the students most in need of intercultural experiences and skills. It would also prompt a more fundamental shift in university culture and expectations. The second reason for making the programs for-credit is that they allow for accountability and assessment of the participating students. Only by consciously managing the requirements, aims, and structure of the program can universities build connections and encourage relationships that would not exist otherwise.

The key to these programs is to build a bridge that helps students engage with members of the community that they cannot access easily on their own. In turn, it will make a small step towards altering the community's conceptualization of international students and the students' experience of that community. Although the concept of community-based projects is not new, such service-learning provides the unique opportunity to benefit both the provider and the recipient (Furco, 1996). Thus, it is our belief that such projects would provide a valuable opportunity to restructure students' relationships to the community when adhering to the three main points described above: facilitated relationships, for-credit value, and purposeful activities that keep the international students in mind and consciously promote cross-cultural understanding. As a result, domestic and international students alike would be exposed to new aspects of the community, would be seen as a valuable resource, and would be engaged in a socially-benefiting action together in which each member is a vital piece of the final product.

\section{Practical Step 2: Establishing Safeguards Against Exploitation}

One of the ways that universities should work together with the community would be in establishing safeguards against exploitation. This would involve connecting with homeowners, employers, community boards, and advocacy groups in establishing guidelines and policies that will be enforceable and actionable. Exploitation continues to take shape only when there is no other competitive option. Importantly, the students also need to be seen as a responsible party, but not as the sole decision-maker. In focusing only on informing the students of their rights, universities continue to place primary responsibility onto the students, the exact population that is vulnerable to exploitation. So, it does not make sense to simply focus on "better informing" students when it is the complex relationship between circumstances, limited opportunities, and need that fosters exploitative situations.

At the same time, it is unreasonable to believe that all universities can simply offer more housing and employment options themselves. While 
doing so is certainly an invaluable way to increase students' opportunities, such expansion may not be possible.

Instead, we suggest that agreements made between the university and the community parties be written down, officially endorsed, and held to some type of actionable enforcement. It is essential that the agreements include not only what is expected of each party, but also what will be explicitly unacceptable. Parties that have established written agreements with the university, such as rental agencies, homestay companies, employers, or employment agencies, can be advertised as "verified" and receive the benefits of university endorsement. Then, if the agreement is broken, the university would be responsible for ending its endorsement of that agency, advertising that the party has broken their agreement, and establishing an agreement with an alternate party. Ideally, agreements will be arranged with two or more parties of the same kind (e.g., rental agencies) to lessen the likelihood of exploitation due to lack of options.

Next, for more serious offenses, arrangements with community boards or local law enforcement need to be instituted that would have the power to punish exploiters either via fine, legal action, or the revoking of licenses and permits. This would not only ensure that students have more options in the case of difficulty, it would also serve to tell potential community partners that mechanisms have been established to keep them accountable.

The implementation of this step also requires that there is indeed a mechanism set up to review and monitor each party's compliance. Most importantly, though, is that students have a place and process to report their concerns and that action is taken on their behalf. It works in neither the community's nor the university's favor to have international students taken advantage of, undercutting established worker laws, or at physical or emotional risk.

\section{Practical Step 3: Streamline Information}

University-community partnerships should next focus on streamlining information related to accommodation issues and advocacy. We acknowledge that many universities have already established accessible information hubs for students regarding housing. However, at many institutions, information is scattered across a variety of organizations, including student associations, university housing offices, advocacy groups, and accommodation posting boards. This makes it difficult for students to know where to go when questionable circumstances arrive or when trying to make smart, preventative decisions. Having a safe living environment is a fundamental requirement for a satisfying study experience, and universities 
must acknowledge that unsafe living environments can lead to undue stress and danger for their students. Thus, once they have accepted their new role as outlined above, universities' next step would necessarily be to actively include the students in a mutual understanding of what is acceptable.

After all, while some homeowners or agents may turn a blind eye and others play active roles in encouraging unfavorable housing circumstances, still others may be unaware that their units are being sublet to so many students. At the same time, many students consciously accept overcrowded living environments because they feel it is their best option, either because they are the cheapest solutions or because traditional means are inaccessible. Just as we insist that the community be held accountable, so too must the students. Yet punishing students when there is no seemingly viable alternative would be unethical.

\section{CONCLUSION}

We understand that each university has its own needs, systems, and priorities and that the steps outlined above will need to be adapted for each institution's particular context. Furthermore, we acknowledge that each university may have existing versions of one or more of these suggested approaches. What we contend, though, is that one piece is not sufficient by itself. Instead, it is necessary that the approach be holistic, structured, and done under the understanding that the university become the students' advocate. These suggestions are also certainly not exhaustive. The premise remains, though, that the university would benefit from taking a more active role in linking international students to the greater community.

It is time to attempt new approaches and strategies to internationalization and in fostering interaction between international students, domestic students, and the wider community. The four points outlined here offer a starting point for expanding internationalization efforts into the greater community. While we strongly believe that such a shift in approach is necessary for improving the international student experience, it is far beyond the scope of this article to propose ways to completely eliminate racism and prejudice, even specifically prejudice towards international students. However, taking steps to reduce issues of exploitation and cultural segregation will help establish a more tolerant, supportive learning environment for all students. By creating a more solidified bridge into the community, the us-versus-them mentality has fewer opportunities to thrive. Furthermore, this fundamental shift in attitude from one of "information providing" to one of "connection building" can help make the student-community benefits more reciprocal and increase cross-cultural 
involvement and understanding on behalf of all students, international and domestic.

\section{REFERENCES}

Akanwa, E.E. (2015). International students in western developed countries: History, challenges, and prospects. Journal of International Students, 5(3), 271-284.

Arambewela, R., \& Hall, J. (2013). The interactional effects of the internal and external university environment, and the influence of personal values, on satisfaction among international postgraduate students. Studies in Higher Education, 38(7), 972-988.

Arkoudis, S., \& Baik, C. (2014). Crossing the interaction divide between international and domestic students in higher education. HERDSA Review of Higher Education, 1, 47-62.

Arkoudis, S., Baik, C., Marginson, S., \& Cassidy, E. (2012). Internationalising the student experience in Australian tertiary education: Developing criteria and indicators. Melbourne: Centre for the Study of Higher Education.

Arkoudis, S., Hawthorne, L., Baik, C., Hawthorne, G., O’Loughlin, K., Leach, D., \& Bexley, E. (2009). The impact of English language proficiency and workplace readiness on employment outcomes and performance of tertiary international students. Melbourne: Centre for the Study of Higher Education, University of Melbourne.

Arkoudis, S., Yu, X., Baik, C., Borland, H., Chang, S., Lang, I., Lang, J., Pearce, A., \& Watty, K. (2010). Finding common ground: Enhancing interaction between domestic and international students. Sydney: ALTC.

Baik, C., \& Greig, J. (2009). Improving the academic outcomes of undergraduate ESL students: The case for discipline-based academic skills programs, Higher Education Research \& Development, 28(4), 401-416.

Barron, P. (2006). Stormy outlook? Domestic students' impressions of international students at an Australian university. Journal of Teaching in Travel \& Tourism, $6(2), 5-22$.

Beelen, J., \& Jones, E. (2015). Redefining internationalization at home. In A. Curaj, L. Matei, R. Pricopie, J. Salmi, \& P. Scott (Eds.), The European higher education area (pp. 59-72). Cham: Springer International Publishing.

Bianchi, C. (2013). Satisfiers and dissatisfiers for international students of higher education: An exploratory study in Australia. Journal of Higher Education Policy and Management, 35(4), 396-409.

Centola, D., Gonzalez-Avella, J.C., Eguiluz, V.M., \& San Miguel, M. (2007). Homophily, cultural drift, and the co-evolution of cultural groups. Journal of Conflict Resolution, 51(6), 905-929.

Deloitte Access Economics. (2016). The value of international education to Australia. Australian Government, Canberra, Australian Capital Territory.

Department of Education and Training. (2017). Higher Education [Data Snapshot]. 2016 International Student Survey Results. Retrieved 24 Oct 2017 from https://internationaleducation.gov.au/research/research-papers/Documents/ED170018\%20International\%20Student\%20Survey\%20HIGHER\%20EDUCATION\% 20Infographic_ACC.pdf 
Dimitrov, N., Dawson, D.L., Olsen, K.C., \& Meadows, K.N. (2014). Developing intercultural competence of graduate students. Canadian Journal of Higher Education, 44(3), 86-103.

Dunne, C. (2009). Host students' perspectives of intercultural contact in an Irish university. Journal of Studies in International Education, 13(2), 222-239.

Dunne, C. (2013). Exploring motivations for intercultural contact among host country university students: An Irish case study. International Journal of Intercultural Relations, 37(5), 567-578.

Edgeworth, K., \& Eiseman, J. (2007). Going Bush: International student perspectives. Retrieved from http://jrre.vmhost.psu.edu/wp-content/ uploads/2014/02/22-9.pdf

Etherington, S. J. (2014). But science is international! Finding time and space to encourage intercultural learning in a content-driven physiology unit. Advances in Physiology Education, 38, 145-154.

Furco, A. (1996). Service-learning: A balanced approach to experiential education. In J. Raybuck (Ed.), Expanding boundaries: Service and learning (pp. 2-6). Washington, D.C.: Corporation for National Service.

Gautam, C., Lowery, C. L., Mays, C., \& Durant, D. (2016). Challenges for global learners: A qualitative study of the concerns and difficulties of international students. Journal of International Students, 6(2), 501-526.

Gribble, C. (2014). Employment, work placements \& work integrated learning of international students in Australia. International Education Association of Australia, Research Digest, 2.

Group of Eight Australia. (2014). International students in higher education and their role in the Australian economy.

Halualani, R. T. (2008). How do multicultural university students define and make sense of intercultural contact? International Journal of Intercultural Relations, 32(1), $1-16$.

Halualani, R. T. (2010). Intercultural interaction at a multicultural university: Students' definitions and sensemakings of intercultural interaction. Journal of International and Intercultural Communication, 3(4), 304-324. https://doi.org/10.1080/17513057.2010.510607

Harrison, N. (2015). Practice, problems and power in "internationalisation at home": critical reflections on recent research evidence. Teaching in Higher Education, 20(4), 412-430.

Harrison, N., \& Peacock, N. (2010). Cultural distance, mindfulness and passive xenophobia: Using Integrated Threat Theory to explore home higher education students' perspectives on "internationalisation at home." British Educational Research Journal, 36(6), 877-902.

ICEF Monitor. (2016). Four megatrends that are changing the competitive landscape of international education. ICEF Monitor-Market intelligence for international student recruitment. (1 Nov 2016). Retrieved 24 July 2017, from http://monitor.icef.com/2016/11/four-megatrends-changing-competitivelandscape-international-education/

Jones, E., \& de Wit, H. (2014). Globalized internationalization: Implications for policy and practice. Management, 33, 95-104. 
Khawaja, N. G., \& Stallman, H. M. (2011). Understanding the coping strategies of international students: A qualitative approach. Australian Journal of Guidance and Counselling, 21(02), 203-224.

Kinnaird, B. (2015). Foreign students exploited as temporary workers. University Work News, 00479. 23 Oct. Retrieved 19 Oct 2017, from http://www.universityworldnews.com/article.php?story=20151020195810258

Knight, B. (2017). No privacy, no space and no support: foreign students describe tough times in Melbourne. ABC News, 12 May. Retrieved 23 October 2017 from http://www.abc.net.au/news/2017-05-12/victoria-foreign-students-describetough-times-in-melbourne/8522640

Koen, J., \& Durrheim, K. (2010). A naturalistic observational study of informal segregation: Seating patterns in lectures. Environment and Behavior, 42(4), 448468.

Kondakci, Y., Van den Broeck, H., \& Yildirim, A. (2008). The challenges of internationalization from foreign and local students' perspectives: The case of management school. Asia Pacific Education Review, 9(4), 448-463.

Kormos, J., Csizér, K., \& Iwaniec, J. (2014). A mixed-method study of languagelearning motivation and intercultural contact of international students. Journal of Multilingual and Multicultural Development, 35(2), 151-166.

Lantz-Deaton, C. (2017). Internationalisation and the development of students' intercultural competence. Teaching in Higher Education, 22(5), 532-550.

Lee, J.J. (2007). Neo-racism toward international students. About Campus, 11(6), 28-30.

Lee, J.J., \& Rice, C. (2007). Welcome to America? International student perceptions of discrimination. Higher Education, 53(3), 381-409.

Lunn, J. (2008). Global perspectives in higher education: Taking the agenda forward in the United Kingdom. Journal of Studies in International Education, 12(3), 231254.

Norton, A. (2016). Mapping Australian higher education 2016. Carlton: Grattan Institute.

O’Reilly, A., Hickey, T., \& Ryan, D. (2013). Higher education professionals' perspectives on international student experiences of life and learning in Ireland: A qualitative study. Irish Educational Studies, 32(3), 355-375.

Parsons, R. L. (2010). The effects of an internationalized university experience on domestic students in the United States and Australia. Journal of Studies in International Education, 14(4), 313-334.

Pham, L., \& Tran, Y. (2015). Understanding the symbolic capital of intercultural interactions: A case study of international students in Australia. International Studies in Sociology of Education, 25(3), 204-224.

Proctor, D., \& Arkoudis, S. (2017). Internationalisation of Australian higher education: Where to from here? In R. James, S. French, \& P. Kelly (Eds.), Visions for Australian tertiary education (pp. 123-132). Melbourne: Centre for the Study of Higher Education, The University of Melbourne.

Ritter, Z.S. (2016). International students' perceptions of race and socio-economic status in an American higher education landscape. Journal of International Students, 6(2), 367-393.

Rochecouste, J., \& Oliver, R. (2014). English language growth and the international student. HERDSA Review of Higher Education, 1, 63-81. 
Romerhausen, N.J. (2013). Strategies to enhance student success: A discourse analysis of academic advice in international student handbooks. Journal of International Students, 3(2), 129-139.

Ryan, R., Dowler, B., Bruce, S., Gamage, S., \& Morris, A. (2016). The wellbeing of international students in the city of Sydney. Sydney: University of Technology Sydney, Institute for Public Policy and Governance Sydney.

Seow, M.A. (2005). The changing profile of the international students: Understanding the student with status from previous study. Paper presented at the IDP conference, Queensland, Australia.

Smith, G.A., \& Sobel, D. (2010). Place- and community-based education in schools. New York: Routledge

Straker, J. (2016). International student participation in higher education: Changing the focus from "international student" to "participation." Journal of Studies in International Education, 20(4), 299-318.

Strauss, P., U-Mackey, A., \& Crothers, C. (2014). "They drag my marks down!"challenges faced by lecturers in the allocation of marks for multicultural group projects. Intercultural Education, 25(3), 229-241.

Sweeney, A., Weaven, S., \& Herington, C. (2008). Multicultural influences on group learning: A qualitative higher education study. Assessment \& Evaluation in Higher Education, 33(2), 119-132.

Tovey, J. (2009). Promises, then the reality for foreign students. The Sydney Morning Herald, 15 July. Retrieved 23 Oct 2017 from http://www.smh.com.au/national/promises-then-the-reality-for-foreign-students20090714-dk5h.html

Tran, L., \& Gribble, C. (2015). Foreign students have a valuable contribution to make. University World News, 00479, 23 Oct. Retrieved 19 Oct 2017 from http://www.universityworldnews.com/article.php?story=20151020202131169

Vickers, P., \& Bekhradnia, B. (2007). The economic costs and benefits of international students. Oxford: Higher Education Policy Institute.

Yates, L., \& Wahid, R. (2013). Challenges to brand Australia: International students and the problem with speaking. Higher Education Research \& Development, 32(6), 1037-1050.

$\mathrm{Yu}$, B., \& Wright, E. (2016). Socio-cultural adaptation, academic adaptation and satisfaction of international higher degree research students in Australia. Tertiary Education and Management, 22(1), 49-64.

Zhang, Y. (2015). Intercultural communication competence: Advising international students in a Texas community college. NACADA Journal, 35(2), 48-59.

SAMANTHA MARANGELL, EdM, MA, is a doctoral candidate at the Centre for the Study of Higher Education at the University of Melbourne, under the supervision of Professor Sophie Arkoudis and Dr. Chi Baik. Her research focuses on the relationship between international and domestic students and their expectations of internationalized institutions of higher education. Email: smarangell@student. unimelb.edu.au

SOPHIE ARKOUDIS, PhD, is a Professor in the Centre for the Study of Higher Education, University of Melbourne. Her major research interests lie in internationalization, English language standards in higher education, the student experience, and quality of teaching and learning. Email: s.arkoudis@unimelb.edu.au 
CHI BAIK, PhD, is an Associate Professor in the Centre for the Study of Higher Education, University of Melbourne. Her major research interests lie in curriculum design, internationalization, the quality of university teaching, and the student experience. Email: cbaik@unimelb.edu.au

Manuscript submitted: November 29, 2017

Manuscript revised: March 12, 2018 Accepted for publication: April 1, 2018 